Esta revista forma parte del acervo de la Biblioteca Jurídica Virtual del Instituto de Investigaciones Jurídicas de la UNAM

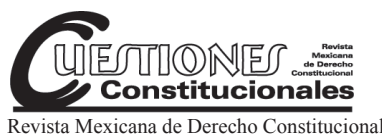

Revista Mexicana de Derecho Constitucional

Núm. 37, julio-diciembre 2017

\title{
INDETERMINACIÓN Y CONTENIDO \\ ESENCIAL DE LOS DERECHOS HUMANOS \\ EN LA CONSTITUCIÓN MEXICANA
}

\author{
INDETERMINATION AND CONTENT \\ ESSENTIAL OF HUMAN RIGHTS \\ IN THE MEXICAN CONSTITUTION
}

\section{Rogelio LÓPEZ SÁNCHEZ*}

RESUMEN: La garantía del contenido esencial de los derechos fundamentales está ausente en la ley fundamental mexicana. Por este motivo, para encontrar un fundamento hermenéutico que provea de certeza a los diferentes ordenamientos legales es necesario buscar en la jurisprudencia mexicana. Este trabajo de investigación se ocupa de la tesis de la configuración de los derechos fundamentales a través del principio de proporcionalidad, el cual es empleado para concretar el contenido esencial de los derechos humanos.

Palabras clave: contenido esencial, derechos humanos, Constitución mexicana.
ABSTRACT: The guarantee of essential content in fundamental rights is absent in mexican basic Law. Therefore, in order to find an hermeneutical fundament that provides certainty different legal orders it's necessary to seek in mexican jurisprudence. This research paper deals with the thesis of configuration of fundamental rights trough the principle of proportionality which is used to specify the essential content of human rights.

Key words: essential content, human rights, mexican Constitution.

* Profesor-investigador en la Facultad de Ciencias Políticas y Administración Pública de la Universidad Autónoma de Nuevo León; miembro del Sistema Nacional de Investigadores nivel I. 
Esta revista forma parte del acervo de la Biblioteca Jurídica Virtual del Instituto de Investigaciones Jurídicas de la UNAM

SUMARIO: I. Introducción: la tesis de la indeterminación normativa. II. Las normas de derechos fundamentales como principios dúctiles: su carácter indeterminado. III. Los límites a los derechos fundamentales a través del criterio material y estructural. IV. La garantía del contenido esencial de los derechos fundamentales: su estructura y desarrollo. V. Conclusión. VI. Bibliografía.

\section{INTRODUCCIÓN: LA TESIS DE LA INDETERMINACIÓN NORMATIVA}

Hart, uno de los juristas de la teoría del derecho más influyentes del siglo $\mathrm{XX}$, defendía la tesis de la textura abierta del derecho a partir de una premisa muy sencilla: "la razón está en que la necesidad de tal elección nos es impuesta porque somos hombres y no dioses". ${ }^{1}$ Ante dicha situación, el juez cuenta con un margen de discrecionalidad judicial ante el desconocimiento de los hechos futuros, así como la existencia de zonas de penumbra, casos que los podemos clasificar como difíciles. La indeterminación, imprecisión y la vaguedad de las normas jurídicas, ${ }^{2}$ son características inherentes al proceso de constitucionalización del ordenamiento jurídico. ${ }^{3}$

Desde una óptica formalista se ha criticado que estas "cualidades" representan síntomas negativos, más bien considero que este proceso debe ser visto desde la dinámica del neoconstitucionalismo ${ }^{4}$ como un elemento positivo para abonar hacia el respeto de la pluralidad y la coexistencia de valores, que en ocasiones no son suficientes de aprender por el legislador al momento de elaborar las normas jurídicas. ${ }^{5}$ En este contexto, el objeto

1 Hart, L. A., El concepto del derecho, trad. de Genaro R. Carrió, Buenos Aires, Abeledo Perrot, 1998, p. 160.

2 Endicott, Timothy A.O., "El derecho es necesariamente vago", trad. de J. Alberto del Real Alcalá y Juan Vega Gómez, Derechos y Libertades, núm. 12, 2003, pp. 184 y 189.

3 Moreso, J. J., La indeterminación del derecho y la interpretación de la Constitución, Madrid, Centro de Estudios Políticos y Constitucionales, 1997, pp. 183 y ss; Guastini, Riccardo, Interpretar y argumentar, Madrid, Centro de Estudios Políticos y Constitucionales, 2014, p. 45.

4 Escudero, Rafael, "La respuesta positivista al desafío del neoconstitucionalismo: el positivismo jurídico incluyente", en Pozzolo, Susana (coord.), Neoconstitucionalismo, derecho y derechos, Lima, Palestra, 2014, pp. 89-118.

5 Real, J. Alberto del, "La «doctrina de la completitud» del derecho según el antipositivismo jurídico contemporáneo”, en Varios autores, Teoría y metodología del dere- 
Esta revista forma parte del acervo de la Biblioteca Jurídica Virtual del Instituto de Investigaciones Jurídicas de la UNAM

de estudio en este capítulo es la garantía del contenido esencial de los derechos fundamentales, como una institución de la dogmática constitucional que permite al intérprete judicial concretar el contenido de los enunciados normativos de derechos humanos ante casos difíciles. Pegoraro ha precisado sobre la indeterminación de las normas constitucionales lo siguiente:

...son los mismos tribunales quienes individualizan los valores $-\mathrm{y}$ los que deciden, por tanto, qué representa dicho «valor» merecedor de tutela-y quienes le atribuyen, en un momento histórico, una posición privilegiada respecto a los demás, según una interpretación de la realidad que no siempre está en sintonía con la visión que de la misma tienen otros órganos o sujetos políticos, pero que presumen sea conforme con aquello que expresa la sociedad. ${ }^{6}$

En esta sección me avocaré al estudio de esta institución desde la óptica de la dimensión objetiva y subjetiva de los derechos fundamentales, enfatizando la importancia de esta garantía institucional del contenido esencial para concretarla en aquellos casos difíciles, resueltos por los jueces constitucionales. Para cumplir este objetivo realizaré, en primera instancia, un estudio sobre la tesis de la indeterminación y completitud de los sistemas jurídicos.

Tenemos ante nosotros dos paradigmas en apariencia contradictorios. El primero, el de la completitud del derecho, defiende en encontrar en el propio ordenamiento la solución a todos los casos posibles; mientras que el segundo, indeterminación normativa, admite la posibilidad de creación del derecho por los propios tribunales. En este camino, me apoyaré en autores como Kelsen y Dworkin (completitud), así como Hart y Endicott (indeterminación y discrecionalidad judicial). En tal sentido, expondré las tesis principales en torno a las tesis de indeterminación y completitud de los autores señalados, con el fin de que esto sirva para fundamentar el control de constitucionalidad que ejerce el juez constitucional al momento de concretar las normas de derechos fundamentales.

Siguiendo con esta idea continuaré con el desarrollo de la tesis interna y externa de los límites a los derechos fundamentales, a partir del criterio material y estructural. En la siguiente sección analizaré la garantía, objeto

cho. Estudios en homenaje al profesor Gregorio Peces-Barba, Madrid, Dykinson, vol. II, 2008, p. 428.

6 Pegoraro, Lucio, La justicia constitucional. Una perspectiva comparada, trad. de Marta León Alonso, Madrid, Dykinson, 2004, p. 126. 
Esta revista forma parte del acervo de la Biblioteca Jurídica Virtual del Instituto de Investigaciones Jurídicas de la UNAM

de estudio, a partir de las posturas absolutas e intermedias más reconocidas en la dogmática de los derechos fundamentales. Por último, situándome en una dimensión objetiva, propongo la aplicación matizada del principio de proporcionalidad desde una teoría relativa del contenido esencial, así como la aplicación de una teoría material de los derechos fundamentales.

\section{La completitud de los sistemas normativos}

Hans Kelsen, autor de la Teoría pura del derecho, brinda un esquema de interpretación y explicación del modelo normativo, a partir de la construcción conceptual de sus distintas figuras, como la norma jurídica fundamental, la cual dota de validez al resto del ordenamiento jurídico. ${ }^{7}$ Este intento por crear una teoría pura del derecho ha merecido serias críticas sobre su pretendida pureza, en el sentido de ser así misma "impura", ya que: "Valora opciones metódicas y propugna como mejor una de ellas; en cuanto que incluso se presenta a sí misma como teoría una de ellas, como es el positivismo". ${ }^{8}$

Siguiendo esta tesis, el operador jurídico debe encontrar todas las respuestas en el derecho positivo, incluso, ante la existencia de conflictos entre normas, resolverá a partir de principios que el propio derecho positivo brinda: "El conflicto entre normas no es una contradicción lógica, la derogación que resuelve el conflicto no es un principio lógico- como lo creía la jurisprudencia tradicional - sino, la función de una norma de la moral positiva, especial, de una norma del derecho positivo". ${ }^{9}$ En caso de que existan lagunas, el jurista debe actuar o debe asumir una posición un tanto engañosa, es decir, debe actuar "como si" aquéllas no existieran; por consiguiente, debe pensarse en el sistema como un conjunto coherente y ausente de imperfecciones.

De acuerdo a esta concepción, los jueces comulgarían con dicha acepción ideológica de que están atados a la ley, de modo que: "La mayoría de las veces ni siquiera serán conscientes de que lo que llaman laguna en realidad

7 Buligyn, E., “An Antinomy in Kelsen's Pure Theory of Law”, Ratio Iuris, núm. 3, 1990, p. 31.

8 García, Juan A., Hans Kelsen y la norma fundamental, Madrid, Marcial Pons, 1996, p. 145.

9 Kelsen, Hans, Teoría general de las normas, México, Trillas, 1994, p. 132; Binddreiter, Uta, Why Grundnorm? A Treatise on the Implications of Kelsen's Doctrine, Londres, Kluwer Law International, 2002, 143. 
Esta revista forma parte del acervo de la Biblioteca Jurídica Virtual del Instituto de Investigaciones Jurídicas de la UNAM

no existe como tal y es algo que ellos mismos crean para sustraerse a una decisión que parece gravemente inconveniente". ${ }^{10}$ Así, la idea de sujeción a la ley será una creencia fuertemente arraigada durante el desarrollo del positivismo jurídico. La doctrina de Kelsen defiende la tesis de completitud del derecho, debido a que éste niega la posibilidad de que existan lagunas en el ordenamiento jurídico, además de una tenue y leve discrecionalidad del operador jurídico. Ahora bien, esta idea de completitud del derecho guarda íntima relación con su concepción de Estado. Al respecto, el jurista de Viena afirmará: “...el Estado como orden, no puede ser más que el orden jurídico o la expresión de su unidad... Si el Estado es un sistema normativo, tiene que ser el orden jurídico positivo, pues es imposible admitir junto a éste la validez de otro orden cualquiera". ${ }^{11}$

El fundamento anterior, al igual que su idea de interpretación forma parte de la doctrina como marco, consiste en que el sistema jurídico provee para sí y para los casos judiciales todas las respuestas a partir del propio ordenamiento. Asimismo, Kelsen admite que la jurisdicción es un acto de creación y producción del derecho, tal y como sucede con el proceso legislativo, éste significará "una sucesión continuada de actos de concreción e individualización crecientes del Derecho". ${ }^{12}$ Sin embargo, su posición en torno a la teoría de las lagunas en el ordenamiento jurídico es equiparable a una ficción, ya que "es lógicamente posible, aun cuando algunas veces resulte inadecuado, aplicar el orden jurídico en el momento de fallar". ${ }^{13} \mathrm{De}$ acuerdo a ello, la teoría de las lagunas será calificada como "errada" por el propio profesor austriaco.

Luego entonces, la teoría del derecho de raíz kelseniana sostiene los caracteres de eficacia, coactividad, unidad, coherencia del ordenamiento jurídico, cuya validez depende directamente de la norma presupuesta, es decir, de la norma de validez fundamental. De forma más refinada y elaborada, los fundamentos de la teoría del positivismo jurídico han sido trasladados a la época actual por Norberto Bobbio. ${ }^{14}$ Por otra parte, la visión

10 García, Juan A., op. cit; p. 159.

11 Kelsen, Hans, Teoría general del Estado, trad. de Luis Legaz y Lecambra, Granada, Comares, 2002, pp. 26 y 27.

12 Ibidem, p. 389.

13 Kelsen, Hans, Teoría general del derecho y del Estado (trad. de Eduardo García Máynez), UNAM, México, p. 177.

14 Bobbio, Norberto, El positivismo jurídico. Lecciones de filosofía del derecho reunidas por el doctor Nello Morra, trad. de Rafael de Asís y Andrea Greppi, Madrid, Deba- 
Esta revista forma parte del acervo de la Biblioteca Jurídica Virtual del Instituto de Investigaciones Jurídicas de la UNAM

teórico-política de Dworkin, a pesar de quedar inscrita bajo el esquema neoiusnaturalista, ${ }^{15}$ sostiene una visión de completitud del ordenamiento jurídico. ${ }^{16}$ El modelo de la función judicial de resolución de casos difíciles postulado por Dworkin es el de la respuesta correcta, denominado como modelo del juez Hércules, relacionado con la interpretación que llevan a cabo los jueces constitucionales. De esta manera:

La Constitución es fundamental para otro derecho, de modo que la interpretación de Hércules de todo el documento, y de sus cláusulas abstractas, también debe ser fundamental. Debe adaptarse y justificar los arreglos básicos del poder político de la comunidad, lo que implica una justificación que surja de los alcances más filosóficos de la teoría política. ${ }^{17}$

De acuerdo a la perspectiva de algunos autores, el jurista de la Universidad de Oxford se acerca más a la idea de la completitud que de la indeterminación, toda vez que es precisamente el juez Hércules el que es capaz de encontrar todas las soluciones posibles a partir de la integración y la interpretación en base a principios; es decir, la teoría dworkiniana defiende un antipositivismo jurídico que alega la completitud del derecho, pues el modelo de juez pugnado por el propio autor se ancla bajo un esquema de indeterminación, pero pide ser tratado "como si" tuviera todas las respuestas. ${ }^{18}$ Precisamente, esta teoría nos brinda la posibilidad de encontrar la respuesta a partir del empleo en la interpretación de las reglas y los principios. Cuando el iusfilósofo americano trata de responder a la cuestión de ¿si el derecho es un sistema de reglas? Contesta negativamente y pretende justificarlo, afirmando que en un sistema jurídico se constituye a partir de una visión reduccionista del positivismo jurídico, sin embargo,

te, 1998 , pp. 240 y 241; Problema del positivismo giuridico, el problema del positivismo jurídico, trad. de Ernesto Garzón Valdés, Editorial Universitaria de Buenos Aires, 1965, p. 18.

15 Dworkin, Ronald, Justice for Hedgehogs, Cambridge, Massachussets, The Belknap Press of Harvard University Press, 2011, p. 1; Los derechos en serio, Madrid, Ariel, 1999, pp. 230 y 233.

16 Pérez, Antonio-Enrique, Trayectorias contemporáneas de la filosofía y la teoría del derecho, Madrid, Editorial Tebar, 2007, pp. 36 y 37.

17 Dworkin, Ronald, El imperio de la justicia. De la teoría general del derecho, de las decisiones e interpretaciones de los jueces y de la integridad politica y legal como clave de la teoría y la práctica, Madrid, Ariel, 1999, p. 267.

18 Real, J. Alberto del, "La doctrina de la completitud..., cit., p. 428. 
Esta revista forma parte del acervo de la Biblioteca Jurídica Virtual del Instituto de Investigaciones Jurídicas de la UNAM

que la misma requiere ser ampliada, a partir de estándares propios del Poder Legislativo, las cuales constituirán las directrices políticas: aquellos objetivos que pretenden ser alcanzados, debido a que éstos implican una mejora en el campo económico, político o social de la comunidad.

Ahora bien, cuando se refiere a los principios explica que éstos constituyen exigencias de justicia, equidad u otra dimensión de moralidad, cuya pertenencia al derecho queda justificada en razón de su contenido, debido a que constituyen un núcleo básico del sistema jurídico. La diferencia entre las reglas y los principios reside en la forma en que se resolverán los posibles conflictos o antinomias en el sistema jurídico. Es decir, cuando dos principios se encuentren en conflicto, dentro de un sistema constitucional, será necesario resolver apelando a consideraciones, que incluso trascienden a la norma misma, tomando el peso de cada principio en colisión. En sentido contrario, las reglas operan en el "todo o nada"; tienen aplicación o no, mientras que los principios son el fruto del acto, de la creación o invención del jurista que resuelve. ${ }^{19}$

Bajo este contexto, Dworkin también elabora una crítica severa en contra del modelo de su antecesor Hart, en el sentido de atacar la idea de la creación del derecho a través de una textura abierta del lenguaje normativo y la discrecionalidad judicial. ${ }^{20}$ En este sentido es posible encontrar, incluso para los casos difíciles, la respuesta correcta. Para lograr lo anterior, pugna por el modelo del juez Hércules, mediante la fusión de la teoría de la ética y la teoría constitucional. La visión neoiusnaturalista que sostiene Dworkin influye sin duda alguna en la visión de la resolución de casos. Para él, los conflictos ante la justicia constitucional representan exigencias de principios morales y no otra cosa, de tal suerte que el derecho debe ser compatible con los principios de la moralidad política, lanzando, como ya lo hemos dicho previamente, atrevidas propuestas sobre una posible fusión entre la teoría de la ética y la teoría constitucional. ${ }^{21}$ En el siguiente apartado analizaré la tesis de la indeterminación desde dos perspectivas iusfilosóficas contemporáneas.

19 Dworkin, Ronald, Los derechos..., cit., pp. 60 y ss.

20 Vigo, Rodolfo L., Interpretación jurídica (del modelo iuspositivista legalista decimonónico a las nuevas perspectivas), Buenos Aires, Rubinzal-Culzoni Editores, 1999, p. 48.

21 Dworkin, Ronald, Los derechos..., cit., pp. 230 y 233. 
Esta revista forma parte del acervo de la Biblioteca Jurídica Virtual del Instituto de Investigaciones Jurídicas de la UNAM

\section{La indeterminación y vaguedad del derecho}

En este apartado he decidido plantear un paralelismo entre las tesis de la indeterminación que son defendidas por los autores Hart y Endicott. El primero, autor de la obra El concepto del derecho, sostiene una visión de un juez con un moderado poder discrecional para resolver casos judiciales, a través de un replanteamiento del positivismo jurídico, y la aceptación y reconciliación explícita entre el derecho y la moral que habían permanecido por décadas soslayadas, debido al fuerte arraigo del método positivista de corte kelseniana. Por otra parte, Endicott, autor de La vaguedad en el derecho, defiende una postura bastante peculiar, en torno a la vaguedad como condición inescindible de los sistemas jurídicos. En este sentido, ambos defienden y pugnan por la idea del derecho incierto e indeterminado, a través de caminos no tan distintos, como presentaré a continuación.

La rehabilitación del análisis entre la moral y el derecho que realiza Hart es primordial para tener una comprensión holística e integral del fenómeno en cuestión. La noción del jurista de Oxford no tiene que ver con un sistema de reglas (teoría de interpretación), su noción es, más bien, una dirección de tres aspectos: el derecho, la coerción y la moral. ${ }^{22}$ En todos los casos de la experiencia, no sólo en el de las reglas, se presenta un límite inherente en la naturaleza del lenguaje. Existen en igual medida casos obvios, fáciles, que aparecen en contextos similares, donde las expresiones normalmente son claramente aplicables. Sin embargo, también existen casos frente a los que no resulta claro si aquéllas se aplican o no. Estos últimos casos son situaciones de hecho, que la naturaleza o la inventiva humana presentan a diario, y que sólo exhiben algunas características del caso obvio, mientras que les faltan otras. ${ }^{23}$

En un principio, Hart se lanza en contra del formalismo jurídico, advirtiendo que este fenómeno se trata de la incapacidad del operador jurídico para individualizar las reglas a cada caso: "Consiste en una actitud hacia las reglas verbalmente formuladas que procura encubrir y minimizar la necesidad de tal elección, una vez que la regla general ha sido establecida". ${ }^{24}$ De acuerdo a lo anterior, identifica una "zona de penumbra", donde serán ubicados los borderline cases; es decir, fuera del ámbito de aplicación de

22 Hart, H. L. A. (1992), El concepto de..., cit., p. 33.

23 Ibidem, p. 158.

24 Ibidem, p. 161. 
Esta revista forma parte del acervo de la Biblioteca Jurídica Virtual del Instituto de Investigaciones Jurídicas de la UNAM

las reglas. ${ }^{25}$ Sobre esta tipología podríamos destacar los casos marginales, dudosos, indeterminados y difíciles. Frente a los "casos difíciles" no será suficiente la formulación del problema jurídico en base a las reglas, sino que es indispensable el razonamiento a partir de principios y valores. Esta visión conduce hacia un positivismo más incluyente, aceptando, incluso que el derecho positivo debe incluir algún grado de moralidad. Dicho lo anterior, las posiciones en torno a este debate se han agrupado entre quienes defienden el positivismo jurídico en sentido amplio (coactividad, legislativa e imperativa) y quienes se adhieren a un positivismo jurídico en sentido estricto (coherencia, plenitud y mecanicidad). ${ }^{26}$

La concepción de Hart sobre el sistema jurídico se encuentra en contra de la posición hermética del derecho. La idea de la textura abierta y los conceptos jurídicos indeterminados dan posibilidad al intérprete sobre toda una gama de casos dudosos, en donde los jueces tienen la posibilidad "discrecional" acerca de los intereses que se encuentran en conflicto en cada caso en particular, de ahí el área de creación del derecho por los tribunales, a partir de las reglas dadas a cada caso en particular; aquí es donde tiene su arraigo el constitucionalismo de principios, al que me referido en líneas previas. La necesidad de concreción de las normas a través de herramientas que permitan al operador asignar su correcto significado, es una de las tareas más complejas en la interpretación y la argumentación jurídicas. Continuando con esta idea, se encuentra a otro de los autores más significativos y originales de la filosofía del derecho contemporánea. Se trata del pensamiento jurídico del autor Timothy Endicott. Su postura inicial se centra en la idea radical en que la vaguedad es la primera fuente de indeterminación jurídica: ${ }^{27}$

Las leyes pueden ser precisas, pero un sistema jurídico sin leyes vagas es imposible. La razón es que cualquier sistema jurídico necesita regular de un modo general una gran variedad de actividad humana... los estándares

25 Hart, H. L. A., Post scriptum al concepto de derecho, trad., notas y bibliografía de Rolando Tamayo y Salmorán, México, UNAM, Instituto de Investigaciones Jurídicas, 2000, p. 54.

26 Escudero, Rafael, Positivismo y moral interna del derecho, Madrid, Centro de Estudios Políticos y Constitucionales, 2000; Moreso, José Juan et al., Conocimiento jurídico y determinación normativa, México, Fontamara, 2002.

27 Endicott, Timothy A. O., "El derecho es..., cit., pp. 184 y 189. 
Esta revista forma parte del acervo de la Biblioteca Jurídica Virtual del Instituto de Investigaciones Jurídicas de la UNAM

abstractos son vagos, y el Derecho de una comunidad necesariamente incluye estándares abstractos...

Hay una razón final de por qué el Derecho debe ser vago: la regulación de la vida de la comunidad no puede proceder sin considerar a los seres humanos responsables de las acciones.

Es decir, la vaguedad se convierte en un rasgo imprescindible y hasta necesario del propio derecho. De acuerdo con lo anterior, la teoría interpretativa "debe aceptar la indeterminación del derecho como un resultado de la vaguedad en las consideraciones que son relevantes para emitir un juicio"; es decir, aquélla no debería negar la indeterminación del derecho, sino todo lo contrario. ${ }^{28}$ La vaguedad no debe reducirse al aspecto meramente lingüístico, ya que el proceso de interpretación más que resolver indeterminaciones en el derecho implica entonces una "atribución de intenciones de comunicación fácticas o contrafácticas", ${ }^{29}$ la cual será una de las diferencias perceptibles de éste en relación con la tesis de Dworkin.

Siendo por consiguiente la vaguedad un rasgo esencial del derecho, el ideal del imperio de la ley se convierte en una aspiración deseablemente incompleta, pues es imposible que la vida de una comunidad estuviera gobernada completamente por el derecho. "Para tener sentido el imperio de la ley debemos concebirlo como un significado complejo entre la anarquía y la sobre-regulación". ${ }^{30}$ Las "dudas" y el "desacuerdo" serán las responsables de la existencia de una cantidad considerable de casos marginales. A primera vista podríamos pensar que esto se contrapone de alguna forma al ideal de estabilidad y seguridad jurídica sobre el cual quedó cimentado nuestro Estado de derecho durante el siglo XIX. Sin embargo, es precisamente el derrumbe de ese paradigma ante el cual asistimos en el siglo XXI. La presencia de Constituciones invasoras como pluralistas y la coexistencia de valores, en ocasiones contradictorios entre sí, son algunos de los desafíos que se presentan al operador judicial; la certeza en el derecho, como era sostenido antiguamente, no existe más al igual que el hermetismo del sistema jurídico que se aferra al ideal de la seguridad jurídica. Hoy en día los Estados constitucionales van más allá del formalismo, así como los

28 Endicott, Timothy A. O., La vaguedad en el derecho, trad. de J. Alberto del Real Alcalá y Juan Vega Gómez, Madrid, Dykinson, 2007, p. 241.

29 Ibidem, p. 252.

$30 \quad$ Ibidem, p. 287. 
Esta revista forma parte del acervo de la Biblioteca Jurídica Virtual del Instituto de Investigaciones Jurídicas de la UNAM

valores clásicos como la generalidad y abstracción de la ley como únicas e inalterables. ${ }^{31}$

\section{LAS NORMAS DE DERECHOS FUNDAMENTALES COMO PRINCIPIOS DÚCTILES: SU CARÁCTER INDETERMINADO}

Una de las características fundamentales de ese constitucionalismo contemporáneo es la existencia de principios, más allá de la aplicación de reglas de manera mecánica en casos difíciles. Siguiendo entonces la premisa de Zagrebelsky, las sociedades son plurales en la medida en que pugnan por valores diversos y coexisten para dar legitimidad a cada uno de los sectores sociales. ${ }^{32}$ La ductilidad de la Constitución reside en esa coexistencia de valores y principios, cuyo cometido principal es la unidad e integración. En este sentido, el jurista italiano afirma lo siguiente: ${ }^{33}$

La dogmática constitucional debe ser como el líquido donde las sustancias que se vierten - conceptos - mantienen su individualidad y coexisten sin choques destructivos aunque con ciertos movimientos de oscilación... ya que los jueces son garantes de la complejidad estructural del derecho en el Estado Constitucional, de la necesaria y dúctil coexistencia entre ley, derecho y justicia.

Esta acepción se encuentra dirigida en contra del denso formalismo todavía existente en muchos de nuestros sistemas jurídicos, que ha soslayado el aspecto ético inherente de las normas constitucionales. La virtud principal del juez, en la actualidad, es precisamente garantizar la coexistencia de estos tres elementos: ley, derecho y justicia, a través de métodos de interpretación cada vez más dinámicos, y acordes a la realidad social del momento. Por consiguiente, el concepto de Estado de derecho se debe orientar hacia una dialéctica del proceso judicial, siempre inacabado e históricamente abierto.

Particularmente, la historia constitucional, según él autor italiano, debe servir como base fundamental para dotar de sentido y comprender las aspira-

31 Real, J. Alberto del, "Cuestionamiento contemporáneo del ideal de certeza en el derecho: Hart-Zagrebelsky-Endicott”, Boletín Mexicano de Derecho Comparado, México, núm. 131, 2011, p. 694.

32 Zagrebelsky, Gustavo, El derecho dúctil, Madrid, Trotta, 1999, p. 13.

33 Ibidem, pp. 17 y 153. 
Esta revista forma parte del acervo de la Biblioteca Jurídica Virtual del Instituto de Investigaciones Jurídicas de la UNAM

ciones y necesidades de nuestra época, ya que la tradición romano-germana ha estado impregnada por un positivismo jurídico y un formalismo jurídico a ultranza, que ha debilitado e impedido el fortalecimiento y consolidación de los procesos constitucionales. Sobre este punto sostiene: "La historia constitucional no es un pasado inerte sino la continua reelaboración de las raíces constitucionales del ordenamiento que nos es impuesta en el presente por las exigencias constitucionales del futuro". ${ }^{34}$ A través del empleo del método de la historia constitucional, el autor recorre los tres grandes movimientos liberales de declaración de derechos, afirmando la influencia de las tres grandes corrientes del pensamiento político moderno: el liberalismo, el socialismo y el cristianismo social. ${ }^{35}$ De manera que la Constitución deja de ser sólo un sistema de garantías y pretende ser también un sistema de valores, "una norma directiva fundamental": 36

Los jueces continúan cultivando la idea anacrónica de sí mismos, como depositarios de conocimientos eminentemente técnico-jurídicos válidos en cuanto tales, alejándolos de las expectativas que la sociedad pone en ellos sin recibir respuesta.

El legislador debe resignarse a ver sus leyes tratadas como partes del derecho, y no como todo el derecho. Pero puede pretender, tanto de los jueces como de la Corte Constitucional, que se mantengan abiertas las posibilidades de ejercitar su derecho a contribuir políticamente a la formación del ordenamiento jurídico. ${ }^{37}$

La construcción conceptual del derecho dúctil contiene una fuerte crítica en contra del formalismo rígido y de la aplicación mecánica de reglas para resolver los duros y difíciles conflictos en donde se involucran principios y valores constitucionales, ya que: "El derecho como disciplina práctica está anclado a la realidad". ${ }^{38}$ Los principios no determinan el ordenamiento sólo a través de derivaciones deductivas que imiten torpemente a las ciencias lógico-formales. Zagrebelsky se adhiere a una visión principialista del derecho, mediante una dogmática constitucional flexible, y una

\footnotetext{
34 Zagrebelsky, Gustavo, Historia y Constitución, Madrid, Trotta, 2005, p. 91.

35 Zagrebelsky, Gustavo, El derecho..., cit., p. 73.

36 Fioravanti, Maurizio, Los derechos fundamentales, op. cit., p. 133.

37 Zagrebelsky, Gustavo, El derecho..., cit., p. 153.

38 Ibidem, p. 113.
} 
Esta revista forma parte del acervo de la Biblioteca Jurídica Virtual del Instituto de Investigaciones Jurídicas de la UNAM

sistematización estricta a partir del método histórico-constitucional, así como una comprensión de los fenómenos que han incidido en el mismo. Por consiguiente, se encuentra a favor de una discrecionalidad judicial, pero sin responder a otras cuestiones como la indeterminación judicial o la existencia de casos difíciles.

La correcta fundamentación interna y externa es uno de los peldaños en los cuales se respalda la teoría de la argumentación jurídica. Las normas de derecho fundamental, entendidas como "un conjunto de proposiciones que prescriben el deber ser establecido por las disposiciones iusfundamentales de la Constitución", son parte de este entramado teórico en el cual se sustentan. ${ }^{39}$ Bernal Pulido lleva a cabo una clasificación entre normas directamente estatuidas (significado literal de las normas en sentido prescriptivo) y normas adscritas de derechos fundamentales (se fundamentan en las normas directamente estatuidas y que guardan un nexo de contradicción o de identidad con las normas legales, objeto de cada proceso constitucional). ${ }^{40}$

Las mismas normas deben ser dotadas de significado, lo cual implica llevarlo a cabo por distintos medios. Dicho proceso se denomina concretización o concreción, y se define como el acto por medio del cual, el Tribunal Constitucional: "Asevera que una norma adscrita tiene validez definitiva dentro del ámbito de la indeterminación de una disposición de derecho fundamental"; 41 es decir, las normas adscritas ostentan una relación directa con las normas directamente estatuidas, ya que aquéllas tienen su fundamento en éstas. Darle validez definitiva a una norma de derecho fundamental implica asignar un significado concreto: delimitar el contenido esencial del derecho o principio en cuestión, a partir de casos individuales. Abona a lo anterior el contexto de las normas constitucionales y su inherente vaguedad en los términos en los que se encuentran redactadas. La indeterminación semántica, estructural y fáctica, son claros ejemplos del complejo proceso de asignación de significado a los derechos fundamentales. El primer tipo de indeterminación hace referencia a la inexistencia de un significado unitario de los términos utilizados en el derecho fundamental. La indeterminación

39 Alexy, Robert, Teoría de los derechos fundamentales, trad. de Carlos Bernal Pulido, 1ra reimp. de la 2a ed., Madrid, Centro de Estudios Político Constitucionales, 2008, p. 53 .

40 Bernal, Carlos, El principio de proporcionalidad y los derechos fundamentales, Madrid, Centro de Estudios Políticos y Constitucionales, 2009.

41 Hesse, Konrad, Escritos de derecho constitucional, Madrid, Centro de Estudios Políticos y Constitucionales, 2012, p. 40. 
Esta revista forma parte del acervo de la Biblioteca Jurídica Virtual del Instituto de Investigaciones Jurídicas de la UNAM

estructural tiene relación con la univocidad del lenguaje de los derechos, mientras que la indeterminación fáctica tiene relación con la realidad en la que debe quedar subsumida la norma de derecho fundamental. ${ }^{42}$

La indeterminación de las normas constitucionales, como afirma Müller, implica que puedan ser concretadas en menor medida, a partir del texto normativo. De acuerdo con esto, las disposiciones de derecho constitucional no pueden ser aplicadas como meras prescripciones, sino que deben ser concretadas en relación al caso en particular. Lo cual implica alejarse de una visión formal a través de un método que tome en cuenta la realidad social en la que es aplicada una norma de derecho constitucional. ${ }^{43}$ La solución a este complejo problema de indeterminación normativa exige parámetros de control que eviten el vaciamiento del contenido de los derechos fundamentales. Uno de estos criterios es la teoría del contenido esencial de los derechos fundamentales.

\section{LOS LÍMITES A LOS DERECHOS FUNDAMENTALES A TRAVÉS DEL CRITERIO MATERIAL Y ESTRUCTURAL}

Uno de los principales seguidores de la teoría interna de los derechos fundamentales es el jurista alemán Ernst Wolfang Böckenförde, esta idea es continuación de su paradigma en la transformación del Estado de derecho hacia una concepción material. ${ }^{44}$ Después de hacer un repaso sobre los principales métodos tradicionales de interpretación de la ley enunciados por Savigny (gramatical, lógico, sistemático e histórico), Böckenförde manifiesta su clara indisposición para seguir la misma metodología al momento de interpretar normas constitucionales y reducir la indeterminación normativa de las mismas. La razón es clara, se encuentran inspiradas en el derecho romano y constituyen reglas interpretativas propias del derecho privado. Al contrario de las normas ordinarias, la Constitución contiene un

42 Gavara, J. C., Derechos fundamentales y desarrollo legislativo la garantía del contenido esencial de los derechos fundamentales en la ley fundamental de Bonn, Madrid, Centro de Estudios Constitucionales, 1994, pp. 120 y ss.

43 Müller, Friedrich, Métodos de trabajo del derecho constitucional. Fundamentación general de una concepción de los métodos en el trabajo jurídico, Madrid, Marcial Pons, 2006, pp. 267 y ss.

44 Böckenförde, E.W., “Origen y cambio del concepto de Estado de derecho”, Estudios sobre el Estado de derecho y la democracia, trad. y prólogo de Agapito Serrano, R., Madrid, Trotta, 2000, p. 17. 
Esta revista forma parte del acervo de la Biblioteca Jurídica Virtual del Instituto de Investigaciones Jurídicas de la UNAM

denso contenido fragmentario, indeterminado y complejo. Su concepción se adhiere al modelo de Constitución como un orden marco, donde se fijan las reglas procedimentales para el proceso de acción y decisión política. ${ }^{45}$ Después de hacer un repaso de las principales teorías que auxilian la concreción de los derechos fundamentales, el autor concluye con lo siguiente:

Un contenido normativo vinculante no se puede obtener de un texto normativo marco, vago, como es típico para la mayoría de las normas constitucionales, sin recurrir a una teoría de la Constitución (teoría de los derechos fundamentales), a su vez obligatoria, a la que se corresponda la función de directriz normativa para la interpretación.

El análisis de los diferentes métodos de interpretación indica que el punto decisivo para un fortalecimiento o una recuperación de la normatividad de la Constitución - cuando esta es requerida - no descansa en una depuración y meditación metodológica de los singulares pasos interpretativos, por muy importante que estos sean. Más bien, radica en la orientación de la interpretación a un concepto de Constitución, o más exactamente, a una teoría de la Constitución que sea capaz de consignar puntos de vista orientadores y estructuras fundadas en ellos para la interpretación. ${ }^{46}$

Según esta concepción, el proceso de concreción de las normas de los derechos fundamentales viene aparejado con la concepción de una determinada teoría constitucional. Desde mi perspectiva, este punto de vista representa una visión sustancialista de la teoría constitucional. Para este propósito explica la existencia de distintas teorías de derechos fundamentales que auxilian la labor del operador jurídico, al momento de concretizar cada derecho, para lo cual no es necesario llevar a cabo alguna clase de ponderación, pues el derecho se encuentra definido previamente. Esto significa que el contenido de cualquier derecho fundamental puede ser definido prima facie, sin necesidad de ponderación alguna.

Por citar un ejemplo emblemático donde se ha aplicado alguna de estas teorías, se encuentra la jurisprudencia alemana, con el caso de la Ley de Objeción de Conciencia al servicio militar, por los jueces Böckenförde y

45 Böckenförde, E. W., "Los métodos de la interpretación constitucional-inventario y crítica", Escritos sobre derechos fundamentales, prólogo de Francisco J. Bastida, trad. de Juan Luis Requejo Pagés e Ignacio Villaverde Menéndez, Verlagsgesellschaft, Nomos, 1993, pp. 13-43.

46 Ibidem, pp. 34-37. 
Esta revista forma parte del acervo de la Biblioteca Jurídica Virtual del Instituto de Investigaciones Jurídicas de la UNAM

Mahrenholz, quienes formaban parte del Tribunal Constitucional Federal, al que le correspondió juzgar la constitucionalidad de dicha normativa. ${ }^{47}$ De acuerdo a los autores del voto, la fundamentación indebida sobre las fuerzas armadas, inferida de una interpretación sistemática de varios preceptos de la Ley Fundamental de Bonn en consonancia con la teoría del orden objetivo de valores, fue incorrecta, ya que se elevó a rango constitucional la organización y el funcionamiento del ejército.

La idea es proporcionar guías o directrices básicas que fundamenten los criterios a través de los cuales, distintos tribunales constitucionales en el mundo han resuelto casos presentados ante ellos. Una teoría de los derechos fundamentales podemos definirla como "una concepción sistemáticamente orientada acerca del carácter general, los objetivos normativos y el alcance material de los derechos fundamentales". ${ }^{48} \mathrm{La}$ primera se refiere o se encontraría influida por una determinada concepción de Estado y/o una determinada teoría de la Constitución, la cual logra su plena realización cuando los jueces constitucionales resuelven algún conflicto, en la imposición de límites o restricciones a los derechos. ${ }^{49}$ Ambas tienen dos dimensiones: una normativa y otra material. El contenido normativo consiste en una teoría de principios o valores. Por otra parte, la teoría material se encarga de estructurar la argumentación iusfundamental mediante una teoría de principios que los coloque en un orden blando, a través de prioridades prima facie, en aras de los principios de la libertad e igualdad jurídica. En primer término, para la teoría liberal, los derechos fundamentales son derechos de libertad del individuo frente al Estado; es decir, los derechos son establecidos con la finalidad de asegurar la libertad frente a la amenaza estatal, los ámbitos de la libertad individual y social a la que se encuentran expuestos. Dicha teoría tiene varias repercusiones en distintos aspectos: ${ }^{50}$

1. El que los titulares de los derechos fundamentales hagan uso de su libertad, derecho fundamental, así como los motivos y fines que

\footnotetext{
47 BVerfGE 69, 1 (57-87).

48 Böckenförde, E. W., "Teoría e interpretación de los derechos fundamentales", Escritos sobre Derechos Fundamentales, prólogo de Francisco J. Bastida y trad. de Juan Luis Requejo Pagés e Ignacio Villaverde Menéndez, Baden-Baden, Nomos 1993, p. 45.

49 Landa, César, "Teorías de la interpretación constitucional”, en Ferrer, Eduardo (coord.), Derecho procesal constitucional, México, Porrúa, 2002, t. III, p. 2819.

50 Böckenförde, E. W., "Teoría e interpretación..., cit., p. 49.
} 
Esta revista forma parte del acervo de la Biblioteca Jurídica Virtual del Instituto de Investigaciones Jurídicas de la UNAM

persigan es decisión suya, es decir, no puede ser objeto de valoración jurídica.

2. El contenido nuclear o la sustancia de la libertad de los derechos fundamentales conserva su carácter de contenido preexistente frente a las posibles y constitucionalmente admisibles medidas de intervención o delimitación por parte del legislador.

3. Las instituciones jurídicas presentes en el ámbito de un derecho fundamental no tienen ninguna relación directa con el contenido esencial de un derecho fundamental.

4. Finalmente se establece que al Estado no le corresponde ninguna obligación de aseguramiento o garantía para la realización de un derecho fundamental.

Por otra parte, la teoría institucional de los derechos fundamentales ordena ámbitos vitales, objetivos tendentes a la realización de ciertos fines: los derechos bajo esta óptica reflejan circunstancias vitales y, al regularlas, las asumen y les confieren relevancia normativa. De esta manera, la libertad servirá para conseguir determinados objetivos y la actuación del Estado se ve reflejada en forma de regulaciones o sanciones. Entre las principales consecuencias jurídicas de esta teoría para la interpretación de los derechos fundamentales se destacan: ${ }^{51}$

1. La ley se presenta como favorecimiento y realización de la libertad.

2. La libertad de los derechos fundamentales se orienta a determinados intereses, concretamente a la realización del sentido objetivoinstitucional de la garantía de libertad.

3. La garantía institucional de la libertad produce la tendencia a la intangibilidad de las situaciones económicas existentes o de regulación ordinaria en presencia.

El punto de partida de la teoría democrático-funcional de los derechos fundamentales es la concepción de los derechos fundamentales desde su función pública y política, es decir, los derechos fundamentales alcanzan su sentido y su principal significado como factores constitutivos de un libre proceso de producción democrática del Estado y de un proceso democrático de formación de la voluntad política. ${ }^{52}$ Asimismo, entre sus consecuencias destaca:

\footnotetext{
51 Ibidem, p. 53.

52 Ibidem, p. 60.
} 
Esta revista forma parte del acervo de la Biblioteca Jurídica Virtual del Instituto de Investigaciones Jurídicas de la UNAM

1. En ella el contenido y el alcance de la libertad se determina según la función a la que sirven.

2. Se da una fundamentación funcional de la libertad: convierte a la libertad en una competencia.

Por otra parte, la teoría de los derechos fundamentales en el Estado social parte de las:

Consecuencias derivadas de la teoría liberal de los derechos fundamentales y de la organización de la libertad del Estado de derecho burgués edificado sobre ella; por otro lado, la sustitución, provocada por el desarrollo de la sociedad general, del espacio vital dominado de autarquía individual, de relaciones y prestaciones sociales efectivas. ${ }^{53}$

Finalmente, se encuentra la teoría axiológica o del orden de valores, proveniente de la teoría constitucional alemana del primer cuarto del siglo XX. En 1928, el jurista alemán Rudolf Smend publicó su obra Constitución y derecho constitucional, en la cual expuso la famosa teoría del orden de valores, que ha servido de base a la teoría de los derechos fundamentales que lleva ese nombre. En este libro el referido jurista desarrolló su teoría jurídica de la integración, $\mathrm{y}$, en especial, la teoría de los derechos fundamentales como factores de integración material y como expresión de un sistema de valores. El iusfilósofo de Basilea entendía a la teoría del Estado como parte de las ciencias del espíritu al igual que lo hacía Hegel. ${ }^{54}$ De acuerdo a este postulado, es la realidad y no el texto literal o la abstracción dogmática las que le dan significado a la Constitución, la cual también forma parte de la realidad del espíritu; a su vez, es integradora y reproduce el proceso de la comunidad política. La función principal del texto fundamental de acuerdo a esto es orientarse hacia dicha realidad, en la que influyen los procesos de integración cultural, política y social de una comunidad. Para ello, el saber que brindan las ciencias del espíritu es fundamental para cumplir con este propósito. A partir de este entendimiento de la teoría del Estado y de la ciencia del derecho constitucional, dividía a la teoría de la integración en tres apartados: ${ }^{55}$

\footnotetext{
53 Ibidem, p. 63.

54 Hegel, G. W. F., "Filosofía del espíritu", Enciclopedia de las ciencias filosóficas, México, Porrúa, 2004, pp. 344-346.

55 Smend, Rudolf, Constitución y derecho constitucional, trad. de José Ma. Beneyto Pérez, Madrid, CEC, 1985, pp. 62-106.
} 
Esta revista forma parte del acervo de la Biblioteca Jurídica Virtual del Instituto de Investigaciones Jurídicas de la UNAM

a) La integración personal formada por los dirigentes políticos (miembros del parlamento, jefes de Estado, burocracia administrativa y judicial);

b) La integración funcional o procesal, que se refiere a las formas de vida que tienden a crear un sentido colectivo, es decir, procesos que producen una síntesis social, representadas en marchas militares, manifestaciones masivas, elecciones, votaciones, los procesos constitucionales, $\mathrm{y}$

c) La integración material u objetiva, que se refiere a un grupo de valores vividos en consonancia por una comunidad (una sociabilidad de las vivencias sustantivas) encarnada en banderas, escudos, territorio, historia, preámbulos, ceremonias políticas, fiestas nacionales, $\mathrm{y}$, por supuesto, los derechos fundamentales.

En este contexto, refiriéndose a la Constitución de Weimar, el maestro alemán apuntaba:

Los derechos fundamentales son los representantes de un sistema de valores concreto de un sistema cultural que resumen el sentido de la vida estatal contenida en la Constitución. Desde el punto de vista político, esto significa una voluntad de integración material; desde el punto de vista jurídico, la legitimación del orden positivo estatal y jurídico. Este orden positivo es válido sólo en cuanto representa este sistema de valores y precisamente por él se convierte en legítimo. ${ }^{56}$

De esta forma, los derechos cumplen con su función integradora al sistematizar el contenido axiológico objetivo del ordenamiento democrático con la aprobación de la mayoría de los ciudadanos. Asimismo, los derechos fundamentales constituyen un sistema coherente que inspira a todas las normas e instituciones del ordenamiento y prescribe las metas políticas a alcanzar. ${ }^{57}$

\section{La tesis de la configuración de los derechos fundamentales}

a través de la teoría interna y externa

La teoría constitucional ha distinguido dos teorías en la restricción de los derechos fundamentales: la teoría interna y la externa. Conforme a la

\footnotetext{
56 Ibidem, p. 212.
}

57 Pérez, Antonio Enrique, Derechos humanos, Estado de derecho y Constitución..., cit., p. 298. 
Esta revista forma parte del acervo de la Biblioteca Jurídica Virtual del Instituto de Investigaciones Jurídicas de la UNAM

primera (interna), existe desde el principio, el derecho con su contenido predeterminado y sus límites concretos. Por tanto, cualquier medida que afecte a su contenido resultará una restricción al mismo. Del otro lado, se encuentra la teoría externa, la cual presupone la existencia de objetivos jurídicos diversos. El contenido del derecho no puede ser definido prima facie, esta clasificación proviene del derecho civil, particularmente de la herencia del derecho romano. Un claro ejemplo de esta teoría externa es la aplicación del principio de proporcionalidad como un instrumento de la hermenéutica constitucional para concretar normas de derecho fundamental. ${ }^{58}$

Müller es un partidario de la teoría interna de los derechos fundamentales, ya que parte de la conexión entre la interpretación y la realidad en la que es aplicada en la Constitución. Después de hacer un repaso sobre los principales métodos de interpretación de la ley distinguidos por Savigny, concluye sobre la necesidad del respeto a los principios constitucionales, así como una interpretación más amplia de las normas constitucionales, cercanas a la realidad en que las mismas se vislumbran, de acuerdo con los casos concretos en los que actúan aquéllas. ${ }^{59}$ En tal sentido, la estructura de las normas jurídicas debe adecuarse a la realidad en la que se encuentran inmersas, ${ }^{60}$ se basa en el ámbito y el programa normativo, retomando este concepto de Pedro de Vega. ${ }^{61}$

En este sentido, la interpretación como la aplicación no pueden ser concebidas como fenómenos aislados. Es indispensable su conexión con la realidad material que las regula. Lo mismo sucede con las normas constitucionales. La constante indeterminación y ambigüedad es una cualidad inherente a aquéllas. En este sentido, la normatividad de los derechos fundamentales no puede agotarse en el tradicional método interpretativo de las normas jurídicas ordinarias, de acuerdo a prescripciones cerradas y herméticas, sino que requieren de precisión al caso concreto. Por consiguiente, dos puntos que serán piedra angular de su teoría son: la concepción de que la norma general no pude predeterminar plenamente los casos individuales a los aplicadores del derecho. Por otra parte, que las decisiones no pueden

58 Borowski, Martín, La estructura de los derechos fundamentales, trad. de Carlos Bernal Pulido, Bogotá, Universidad del Externado de Colombia, 2003, pp. 66 y ss.

59 Müller, Friedrich, Métodos de trabajo del derecho..., cit., pp. 283 y ss.

60 Müller, Friedrich, "Tesis acerca de la estructura de las normas jurídicas”, Revista Española de Derecho Constitucional, año 9, núm. 27, septiembre-diciembre de 1989, p. 113.

61 Vega, Pedro de, La reforma constitucional y la problemática del poder constituyente, Madrid, Tecnos, 1985, p. 213; Müller, Friedrich, Métodos de trabajo..., cit., pp. 89-91. 
Esta revista forma parte del acervo de la Biblioteca Jurídica Virtual del Instituto de Investigaciones Jurídicas de la UNAM

configurarse mediante el empleo de la lingüística (programa normativo), sino que es indispensable el empleo de datos reales (ámbito normativo).

\section{LA GARANTÍA DEL CONTENIDO ESENCIAL DE LOS DERECHOS}

FUNDAMENTALES: SU ESTRUCTURA Y DESARROLLO

La fórmula del contenido esencial de los derechos fundamentales fue plasmada por vez primera en la Ley Fundamental de Bonn de 1949, en su artículo 19.2, ${ }^{62}$ seguida por la Constitución española de 1978, en su artículo 53.1. ${ }^{63}$ Conforme a criterios doctrinales, dicha cláusula se ha definido como aquel ámbito necesario e irreductible de conducta que el derecho protege, con independencia de las modalidades que asuma éste o de las formas en que se manifieste. Se convierte en un límite infranqueable a la actuación tanto de los poderes Legislativo y Ejecutivo, e implica necesariamente la existencia de contenidos limitadores, susceptibles de extraer del significado de las normas. ${ }^{64}$

Existen tres teorías que explican esta institución: la absoluta, la relativa y la mixta. Según la teoría absoluta, el contenido esencial conforma un "núcleo duro del derecho fundamental que puede ser determinado independientemente de argumentos referidos a una ponderación. De esta forma, las restricciones, que caen bajo ese núcleo duro, están prohibidas definitivamente desde el punto de vista constitucional". ${ }^{65}$ Por consiguiente, la ponderación no es enteramente factible en dichas circunstancias. Y esto constituye una de las principales problemáticas, ya que la configuración del contenido queda realizada previamente. Un caso paradigmático en la aplicación de esta teoría, es la concepción que realizó el Tribunal Constitucional español. Dicho órgano señaló en el caso del "Decreto-Ley de Huelga", que el contenido esencial del derecho subjetivo puede determinarse a partir del tipo abstracto, conceptualmente previo al momento legislativo, constituido

62 Sobre la restricción de los derechos fundamentales: (2) En ningún caso un derecho fundamental podrá ser afectado en su contenido esencial.

63 “Artículo 53.1. Los derechos y libertades reconocidos en el Capítulo segundo del presente Titulo vinculan a todos los poderes públicos. Sólo por ley, que en todo caso deberá respetar su contenido esencial, podrá regularse el ejercicio de tales derechos y libertades que se tutelarán de acuerdo con lo previsto en el artículo 161, 1, a)".

64 De Asís, Rafael, El juez y la motivación en el derecho, Madrid, Dykinson, 2006, pp. 103-107.

65 Borowski, Martin, La estructura de los derechos ... cit., p. 97. 
Esta revista forma parte del acervo de la Biblioteca Jurídica Virtual del Instituto de Investigaciones Jurídicas de la UNAM

entonces por: "aquellas facultades o posibilidades de actuación necesarias para que el derecho sea recognoscible como pertinente al tipo descrito". ${ }^{66}$

Una de las defensas más sólidas en torno a la teoría relativa es el pensamiento a partir de la tesis institucional que sostiene Peter Häberle. Sobre este punto, el profesor alemán analiza los derechos fundamentales manteniendo una visión acorde a un sistema unitario y objetivo. Si bien, la Constitución se encuentra caracterizada como un orden objetivo de valores, éstos deben ser concretados y positivizados en el propio texto fundamental. Para concretar el significado de los derechos fundamentales es indispensable una triple función de éstos: la función social (en la medida en que necesitan ser configurados y desarrollados para su ejercicio), como relaciones de condicionabilidad mutua (relacionados entre sí); y, finalmente, como base funcional para la democracia constitucional. Conforme a lo anterior, la garantía y ejercicio de los derechos se caracteriza a través de la unión o conexión entre los intereses individuales y públicos. ${ }^{67}$

Finalmente, una concepción mixta de las anteriores se traduce en el pensamiento de Prieto Sanchís, el cual la ha definido como aquel ámbito que cuando se encuentra sometido a limitaciones que lo hacen impracticable, lo dificultan más allá de lo razonable o lo despojan de la necesaria protección. Esta cláusula obliga a los jueces a adecuarse a los contenidos y principios establecidos por la Constitución. Igualmente, a pronunciarse sobre la misma forma en todos los casos en que estuviera en juego un derecho fundamental. ${ }^{68}$ Dicho lo anterior, esta cláusula debe respetarse en cualquier acto de autoridad (leyes o actos), ante una posible limitación o necesidad de justificar limitaciones para la preservación de otros bienes constitucionales. De esta forma, el legislador o el Estado, en ejercicio de su actividad ejecutiva, únicamente puede establecer límites o restricciones en la parte accesoria del derecho fundamental. ${ }^{69}$ Por otra parte, la teoría relativa explica que el contenido esencial es aquello que queda después del ejercicio de ponderación respectivo, ante otros bienes o principios

66 Sentencia del Tribunal Constitucional español del 8 de abril de 1981, recaída al recurso de inconstitucionalidad 192/1981.

67 Häberle, Peter, La garantía del contenido esencial de los derechos fundamentales en la Ley Fundamental de Bonn, Madrid, Dykinson, 2008, pp. 34 y ss.

68 Prieto, Luis, "La limitación de los derechos fundamentales", en Neoconstitucionalismo, derechos fundamentales y ponderación judicial, cit., p. 60.

69 Martínez, Antonio Luis, La garantía del contenido esencial de los derechos fundamentales, Madrid, Centro de Estudios Constitucionales, 1997, p. 22. 
Esta revista forma parte del acervo de la Biblioteca Jurídica Virtual del Instituto de Investigaciones Jurídicas de la UNAM

que deben ser tutelados por el Estado, reduciendo, por consiguiente, el contenido esencial al ejercicio que se lleva a cabo a través del principio de proporcionalidad. ${ }^{70}$ En México, el Poder Judicial de la Federación ha reconocido la teoría tanto interna como externa de los derechos fundamentales, como instrumento para dotar del contenido esencial a los derechos humanos de la siguiente manera:

La teoría del contenido esencial de los derechos fundamentales establece que contienen un núcleo fijo e inmutable, de manera que cualquier afectación a éste resulta ilícita, y sólo en su periferia pueden establecerse las limitaciones y restricciones necesarias y justificadas, así como expandirse las condiciones de su ejercicio, partiendo de la base de que estos derechos no son absolutos y su ejercicio está sujeto a límites, más allá de los cuales, éste resulta ilegítimo. ${ }^{71}$

Por su parte, la adopción como criterio hermenéutico de esta teoría ha sido utilizada en la interpretación del principio de seguridad jurídica, mediante la aplicación del principio de proporcionalidad, entendido como interdicción de la arbitrariedad o prohibición del exceso $;^{72}$ en el derecho humano al nombre, ${ }^{73}$ mínimo vital ${ }^{74}$ y acceso a la justicia, ${ }^{75}$ estos últimos desde una dimensión objetiva, así como la restricción de los derechos políticos bajo el esquema de la teoría externa (principio de proporcionalidad

70 Villaseñor Goyzueta, C. A., Proporcionalidad y limites de los derechos fundamentales. Teoría general y su reflejo en la jurisprudencia mexicana, México, Porrúa, 2011, p. 123.

71 Registro: 2003269. "DERECHOS FUNDAMENTALES. SUS LÍMITES INTERNOS Y EXTERNOS". Tesis I.4o.A.17 K (10a.), Semanario Judicial de la Federación y su Gaceta, abril de 2013, t. 3, p. 2110.

72 Registro: 2002649. “SEGURIDAD JURÍDICA EN MATERIA TRIBUTARIA. EN QUÉ CONSISTE”. Tesis 1a./J. 139/2012 (10a.), Semanario Judicial de la Federación y su Gaceta, enero de 2013, t. I, p. 437.

73 Registro: 2000213. "DEREChO humano AL NOMBRE. Su SENTIDO Y ALCANCE A PARTIR DE LA CONSTITUCIÓN POLÍTICA DE LOS ESTADOS UNIDOS MEXICANOS Y A LA LUZ DE LOS TRATAdOS INTERNACIONALES". Tesis 1a. XXV/2012 (10a.), Semanario Judicial de la Federación y su Gaceta, febrero de 2012, t. I, p. 653.

74 Registro: 172546. "DERECHO AL MÍNIMO VITAL. CONSTITUYE UN LÍMITE FRENTE AL LEGISLADOR EN LA IMPOSICIÓN DEL TRIBUTO". Tesis 1a. XCVIII/2007, Semanario Judicial de la Federación y su Gaceta, mayo de 2007, t. XXV, p. 792.

75 Registro: 172577. “CONCEPTOS DE VIOLACIÓN. PARA QUE SE ANALICEN ES INNECESARIO QUE SE MENCIONE EL NOMBRE DEL PRINCIPIO CONSTITUCIONAL QUE SE ESTIMA VIOLAdo. Tesis 2a. XXXVI/2007", Semanario Judicial de la Federación y su Gaceta, mayo de 2007, t. XXV, p. 1183. 
Esta revista forma parte del acervo de la Biblioteca Jurídica Virtual del Instituto de Investigaciones Jurídicas de la UNAM

y razonabilidad). ${ }^{76}$ No obstante, el ejercicio más prolijo para garantizar el contenido esencial de los derechos humanos ha sido a través de la aplicación del principio de proporcionalidad, como explicaré a continuación en el siguiente apartado.

\section{La solución a conflictos de derechos fundamentales a través del principio de proporcionalidad}

El principio de proporcionalidad como criterio hermenéutico-constitucional para lograr la concreción de los derechos fundamentales goza de un gran prestigio en la jurisdicción constitucional, su empleo se ha vuelto común en el derecho público común europeo y latinoamericano. En España fue hasta 1995 el momento en que es receptiva la jurisprudencia de aquel alto tribunal, en materia de principios y valores constitucionales, con la sentencia 66/1995, reconociéndolo como un auténtico criterio para controlar la intervención y restricción a los derechos fundamentales. ${ }^{77}$

No obstante de su aplicación por el Tribunal español, éste ha sido objeto de innumerables concepciones, que lo han llevado a ser objeto de una cantidad considerable de mutaciones conceptuales (criterio, factor, regla, examen). Por su parte, en México su empleo por la SCJN data apenas a principios del presente siglo (2003), con la solución a distintos casos en materia de igualdad y principio de razonabilidad. Para llegar a la ponderación es necesario seguir tres fases escalonadas, conocidas como subprincipios: la adecuación o idoneidad, la necesidad o alternatividad y la proporcionalidad, en sentido estricto. ${ }^{78}$ Este subprincipio se presenta de la siguiente forma: el

76 Registro: 159849. "IGUALDAD Y NO DISCRIMINACIÓN. LOS ARTÍCULOS 16, NUMERAL 3, PÁRRAFO SEGUNDO Y 131, NUMERAL 3, DE LA LEY ELECTORAL DEL ESTADO DE CHIHUAHUA, AL SEÑALAR QUE QUEDAN EXCEPTUADAS DEL PORCENTAJE DE CUOTAS DE GÉNERO AQUELLAS CANDIDATURAS QUE SEAN RESULTADO DE UN PROCESO DE ELECCIÓN DEMOCRÁTICO, CONFORME A LOS ESTATUTOS DE CADA PARTIDO, NO VULNERAN ESOS PRINCIPIOS". Tesis P./J. 14/2013 (9a.), Semanario Judicial de la Federación y su Gaceta, mayo de 2013, t. I, p. 155.

77 Bernal, Carlos, “¿Es la ponderación irracional y contraria al principio democrático? Una discusión sobre la teoría de los derechos fundamentales como principios en el contexto de España", en Sieckmann, Jan-R (ed.), La teoría principialista de los derechos fundamentales (estudios sobre la teoría de los derechos fundamentales de Robert Alexy), Madrid, Marcial Pons, 2011, p. 226.

78 Bernal, Carlos, El principio de proporcionalidad y los derechos fundamentales, Madrid, Centro de Estudios Políticos y Constitucionales, 2007, pp. 693 y ss. 
Esta revista forma parte del acervo de la Biblioteca Jurídica Virtual del Instituto de Investigaciones Jurídicas de la UNAM

medio escogido por el legislador para lograr el objetivo de la norma debe ser idóneo y adecuado, es decir, perseguir una finalidad constitucionalmente legítima. Esta acepción está compuesta de dos elementos: el fin y el medio. Para ello, es imprescindible analizar el fin de la ley que se pretende favorecer, así como el análisis de los medios para conseguirlo.

En principio, un fin legítimo será aquel que no esté en contra de los principios consagrados en el texto constitucional, ya sea que se encuentre la prohibición de manera expresa en el texto fundamental, o se desprenda de algún criterio interpretativo del mismo. ${ }^{79} \mathrm{Al}$ respecto, la profesora Clérico ha indicado que este subprincipio se podría enunciar de la siguiente manera: "Cuando los derechos fundamentales y/o los bienes constitucionales colectivos colisionan y el medio establecido puede fomentar el fin [no i-] legítimo, entonces debe ser examinada la necesidad y proporcionalidad en sentido estricto de la medida (estatal)" ${ }^{80}$ Existen dos versiones para el examen de adecuación técnica: una débil y otra fuerte. Este aspecto se relaciona íntimamente con la discrecionalidad fuerte o débil que ejerce el juez constitucional para evaluar las medidas tomadas por el legislador para alcanzar los objetivos de la norma. Dicho en otras palabras, permite un margen de acción estructural para el examen de adecuación. En este aspecto la versión fuerte de dicho mandato exige que la elección del medio (s) permita alcanzar en la mayor medida posible el fin perseguido por la norma, desde la perspectiva cuantitativa, cualitativa y de probabilidades. ${ }^{81}$ Esta visión o modelo fuerte del principio de adecuación es bastante exigente, ya que en ocasiones determinadas variables son desconocidas al momento de la creación de la norma, escapando por consiguiente del proceso legislativo, y de las demás circunstancias e intereses de los afectados con la vulneración del derecho en cuestión, no solamente al momento de creación de la norma, sino durante toda la vigencia de aquélla.

Para satisfacer de mejor manera el examen de adecuación técnica o idoneidad, el Tribunal Constitucional Federal Alemán ha desarrollado dos formulaciones (una negativa y otra positiva) para determinar si se han satisfecho los requerimientos de este principio. Por una parte, la versión negativa ha quedado delineada de la siguiente manera: “¿Es el medio escogido por el legislador, «inapto objetivamente», «inadecuado objetiva-

\section{Ibidem, p. 704.}

80 Clérico, Laura, El examen de proporcionalidad en el derecho constitucional, Buenos Aires, Editorial Universitaria de Buenos Aires, 2009, p. 39.

81 Ibidem, pp. 59 y ss. 
Esta revista forma parte del acervo de la Biblioteca Jurídica Virtual del Instituto de Investigaciones Jurídicas de la UNAM

mente», «sin más inadecuado», «en principio inadecuado», para fomentar el fin perseguido («o no guarda ninguna relación» o mantiene «ninguna conexión» con el fomento del fin perseguido)?" Por otro lado, la formulación positiva señala: “¿Puede con su ayuda ser fomentado «el resultado deseado»?" 82 Si después de un examen cuidadoso el juez determina que en la aplicación de la regla de la adecuación técnica, aún subsisten dudas sobre si el medio es o no adecuado, de manera abstracta y general debe pasarse a la siguiente fase de la ponderación, que es la regla del medio alternativo menos gravoso (principio de necesidad o elección de medios alternos), para examinar la justificación a la restricción de los derechos invocados, pero sobre todo para evitar el vaciamiento del contenido esencial o núcleo de ambos derechos y optimizar ambos, en la medida de lo posible; es decir, si no existían otros medios o fines menos gravosos para el afectado para cumplir el fin de la norma.

El subprincipio de necesidad se formula de la siguiente manera. El medio establecido en la norma o el acto de autoridad es necesario, si el legislador no pudo elegir otro medio (si bien igualmente adecuado técnicamente), pero que podría haber limitado menos el derecho o principio constitucional afectado. Siguiendo la ley material de la ponderación elaborada por Alexy, esto tiene una explicación sencilla: el legislador o la autoridad no pueden conseguir objetivos o fines de manera desproporcional o innecesaria, si existen medios alternativos menos gravosos para conseguirlo. ${ }^{83}$

Alexy ha elaborado dos leyes para explicar la ponderación: la material y la epistémica. La primera es enunciada de la siguiente forma: "Cuanto mayor sea el grado de interferencia (o no realización) de un principio, tanto mayor debe ser el grado de realización del otro principio". La segunda, de la siguiente manera: "Cuanto más intensa sea una intervención en un derecho fundamental, tanto mayor debe ser la certeza de las premisas que sustentan la intervención". ${ }^{84}$ A diferencia de la primera ley de ponderación, esta segunda ley no enfatiza la importancia material de las razones que sustentan la intervención, sino su calidad epistémica: en el peso factual de la argumentación jurídica. En esta medida, la interferen-

\footnotetext{
82 Ibidem, pp. 61 y ss.

83 Ibidem, pp. 114 y ss.

84 Alexy, Robert, "La fórmula del peso", Teoría de la argumentación jurídica. La teoría del discurso racional como teoría de la fundamentación jurídica, 2a. ed., Madrid, CEPC, 2008, pp. 349-372.
} 
Esta revista forma parte del acervo de la Biblioteca Jurídica Virtual del Instituto de Investigaciones Jurídicas de la UNAM

cia en la realización de cada derecho en conflicto no se debe afectar el contenido esencial de los mismos. Esto significa que las ventajas que se obtienen mediante la intervención legislativa o el acto de autoridad en el derecho fundamental deben compensar los sacrificios que ésta implica para sus titulares y la sociedad, en general. La estructura argumentativa la configura Bernal Pulido en tres pasos:

a) Determinar las magnitudes que deben ser ponderadas, es decir, la importancia de la intervención en el derecho fundamental y la importancia de la realización del fin perseguido por la intervención legislativa.

b) Comparar dichas magnitudes, a fin de determinar si la importancia de la realización del fin perseguido por la intervención legislativa es mayor que la importancia de la intervención en el derecho fundamental.

c) Finalmente, se trata de construir una relación de precedencia condicionada entre el derecho fundamental y el fin legislativo, con base en el resultado de la comparación llevada a cabo en el segundo paso. ${ }^{85}$

Cuando nos encontramos ante dos derechos fundamentales, de igual jerarquía y peso, no se pueden realizar ponderaciones en abstracto. De acuerdo con la teoría de Robert Alexy, la ponderación debe ser llevada a cabo a través de procesos de concreción a partir de las distintas circunstancias en que se desenvuelve cada caso. Ninguna ponderación puede ser igual a otra, esta es una de las distinciones fundamentales entre los casos fáciles de los difíciles. La ley epistémica de la ponderación exige que se evalúen las premisas empíricas de cada caso en particular, tomando en cuenta la magnitud, rapidez, velocidad, probabilidad, alcance, duración, así como la certeza de cada una de las premisas. ${ }^{86}$ A partir de este análisis concienzudo que se efectué entre la afectación a cada peso en concreto, deberá determinase si la afectación a cada derecho resulta ser leve, intermedia o intensa. En la SCJN, la garantía del contenido esencial de los derechos fundamentales ha sido concebida como el resultado del ejercicio del test de proporcionalidad y razonabilidad jurídica, mediante el empleo de una

\footnotetext{
85 Bernal, C., El principio de proporcionalidad..., cit., pp. 693 y ss.

86 Ibidem, p. 791.
} 
Esta revista forma parte del acervo de la Biblioteca Jurídica Virtual del Instituto de Investigaciones Jurídicas de la UNAM

teoría externa de los derechos. ${ }^{87}$ En la ejecutoria del Caso Militares con $V I H$ se advierte lo siguiente: ${ }^{88}$

El principio de unidad de la Constitución exige que los valores y principios que contiene deben interpretarse de manera sistemática, en relación con la totalidad de la Norma Suprema. Es por ello que cuando dos o más normas constitucionales interpretadas literal y aisladamente se contradicen, es preciso armonizar y balancear ambas disposiciones, con el fin de que todas ellas puedan tener eficacia, en alguna medida.

...que el legislador se estime facultado para disponer absolutamente del contenido y eficacia de las garantías individuales, ello conducirá a la posibilidad de que un poder constituido pueda sobreponerse al contenido axiológico y material de la Constitución Federal.

El criterio hermenéutico de concreción empleado por la SCJN en el caso concreto, es desde una óptica material y axiológica de la Constitución. Asimismo, se reconoce la existencia de un contenido irreductible de los derechos fundamentales (contenido esencial), sobre el cual no puede estar ningún poder constituido, argumentando que es en razón de ese contenido axiológico y material, a partir de la cual deben incidir las limitaciones o restricciones legítimas a los derechos. En la última época, los jueces mexicanos han decantando varios criterios en relación con la violación al principio de igualdad a través del análisis de cláusulas sospechosas, por ejemplo, se ha afirmado que este tipo de categorías deben analizarse por medio de un escrutinio estricto, como lo hace la propia Corte Suprema de Estados Unidos, aplicando los subprincipios de adecuación y necesidad, respectivamente. ${ }^{89}$ Un caso ejemplar para ilustrar el empleo del test de escrutinio para detectar posibles violaciones al principio de igualdad de las normas jurídicas (descrita previamente), es el análisis de las normas en aquellas entidades fede-

87 “GARANTÍAS INDIVIDUALES. EL DESARROLLO DE SUS LÍMITES Y LA REGULACIÓN DE SUS POSIBLES CONFLICTOS POR PARTE DEL LEGISLADOR DEBE RESPETAR LOS PRINCIPIOS DE RAZONABILIDAD Y PROPORCIONALIDAD JURÍDICA”. Tesis P./J. 130/2007, Semanario Judicial de la Federación y su Gaceta XXVI, diciembre de 2007, p. 8.

88 Considerando Cuarto del Amparo en revisión 2146/2005, resuelto por el Pleno de la SCJN el 27 de febrero de 2007.

89 "CONSTITUCIONALIDAD DE DISTINCIONES LEGISLATIVAS QUE SE APOYAN EN UNA CATEGORÍA SOSPECHOSA. FORMA EN QUE DEBE APLICARSE EL TEST DE ESCRUTINIO ESTRICTO". Registro: 2003250. Tesis 1a. CI/2013 (10a.), Semanario Judicial de la Federación y su Gaceta, Décima Época, abril de 2013, t. I, p. 958. 
Esta revista forma parte del acervo de la Biblioteca Jurídica Virtual del Instituto de Investigaciones Jurídicas de la UNAM

rativas que no permiten a las parejas homosexuales contraer matrimonio, únicamente contemplan el matrimonio heterosexual. ${ }^{90}$ La discrecionalidad judicial no debe ser entendida como un sinónimo de arbitrariedad, sino como una posibilidad de realización plena del contenido axiológico de las Constituciones del siglo XXI. Esta configuración del Estado y ley fundamental en el neoconstitucionalismo completan el sofisticado andamiaje del renovado y antiguo modelo de Estado de derecho del siglo pasado. Las normas constitucionales son indeterminadas, pero permiten su realización a través de procesos hermenéuticos y argumentativos.

Si bien los antiguos paradigmas para resolver casos judiciales no son erróneos, también es cierto que no funcionan o no sirven para solucionar todos los asuntos que se le presentan al operador de las normas constitucionales. Existen casos complejos, que debido a la multiplicidad de valores en conflicto y la tensión entre uno o más derechos fundamentales involucran en el fondo problemas éticos, donde la axiología constitucional juega un papel trascendental para determinar el equilibrio óptimo y la satisfacción de ambos principios en conflicto. El principio de proporcionalidad debe contener una serie de variables que permitan a los jueces constitucionales garantizar o reforzar las decisiones judiciales. Desde el plano de la praxis judicial, la optimización de los derechos se alcanza mediante la aprehensión de cada una de las variables que intervienen en la afectación de un valor o principio constitucional, tales como la velocidad, rapidez, magnitud, probabilidad, intensidad, con la que son afectados.

La optimización del derecho y la salvaguarda de su contenido esencial es posible, únicamente si se toman en cuenta cada una de las variables que intervienen en cada caso en particular. No es posible una jerarquía predeterminada cuando ocurra una colisión entre valores, la prelación de derechos ocurrirá mediante la aplicación de casos concretos; a pesar de ello,

90 "MATRIMONIO ENTRE PERSONAS DEL MISMO SEXO. Al TRATARSE DE UNA MEDIDA LEGISLATIVA QUE REDEFINE UNA INSTITUCIÓN CIVIL, SU CONSTITUCIONALIDAD DEBE VERIFICARSE EXCLUSIVAMENTE BAJO UN PARÁMETRO DE RAZONABILIDAD DE LA NORMA (ARTíCUlo 146 DEL Código CiVIL PARA EL Distrito FEDERAL, REFORMADO MEDiANTE DECRETO PUBLICADO EN LA GACETA OFICIAL DE LA ENTIDAD EL 29 DE DICIEMBRE DE 2009)". Tesis P. XXIV/2011, Semanario Judicial de la Federación y su Gaceta XXXIV, Novena Época, agosto de 2011, p. 873.

"ESCRUTINIO DE IGUALDAD Y ANÁLISIS CONSTITUCIONAL ORIENTADO A DETERMINAR LA LEGITIMIDAD DE LAS LIMITACIONES A LOS DERECHOS FUNDAMENTALES. SU RELACIÓN." Tesis P./J. 28/2011, Semanario Judicial de la Federación y su Gaceta, XXXIV, Novena Época, agosto de 2011, p. 5. 
Esta revista forma parte del acervo de la Biblioteca Jurídica Virtual del Instituto de Investigaciones Jurídicas de la UNAM

los canones para aplicar correctamente el principio de proporcionalidad se encuentran fijados de antemano (subprincipio de adecuación, necesidad y proporcionalidad en sentido estricto o ponderación).

Desde el plano de la argumentación constitucional es imposible medir o cuantificar el grado de racionalidad de las decisiones judiciales, pretender una racionalidad absoluta implicaría por sí mismo una concepción errónea, no sólo de las herramientas de la argumentación, sino de la propia ciencia jurídica; el balanceo de principios o valores encierra un problema de fondo más complejo: la adhesión del juez constitucional hacia una o varias teorías de derechos fundamentales mediante las cuales asigna un significado concreto a esos derechos, la aplicación del test de proporcionalidad debe ir aparejado con la comprensión de estas teorías, de lo contrario, la aplicación de esta herramienta podría tornarse vacía y carente de sentido.

\section{CONCLUSIÓN}

Los derechos concebidos como principios permiten ejercicios hermenéuticos de corrección y ajuste para resolver a través de esquemas procedimentales y discursivos los conflictos entre dichos valores. Si bien la teoría más aceptada en la comunidad de juristas es la ponderación, se examinaron otras vías de asignación de significado a los derechos mediante la existencia de límites internos e inmanentes, así como las distintas teorías materiales de los derechos fundamentales que ayudan a concretar su significado, sin necesidad previa de alguna ponderación. Las doctrinas para determinar el contenido esencial de los derechos fundamentales son muy importantes porque explican cuál debe ser el contenido de un derecho, a partir de una preconcepción mínima de los mismos, o bien mediante ejercicios hermenéuticos de limitación o restricción fundamentados en la existencia de posibles colisiones y la necesidad de armonizar los principios en tensión. Las dos primeras teorías (subjetiva y objetiva) del contenido esencial se centran en la concepción de los derechos fundamentales como derechos subjetivos, pero también por medio de la comprensión de los derechos como objeto de control de regularidad constitucional.

Dentro de la teoría interna se encuentran posturas radicales, como aquella que defiende de manera absoluta el contenido esencial de los derechos como un ámbito irreductible e indisponible para el juez al momento de resolver casos difíciles. Luego, dicha teoría no admite ponderaciones porque la 
Esta revista forma parte del acervo de la Biblioteca Jurídica Virtual del Instituto de Investigaciones Jurídicas de la UNAM

preconcepción del contenido esencial del derecho se encuentra definida de antemano por el legislador. Esto último se acerca peligrosamente a la imposibilidad del juez para llevar a cabo su labor interpretativa, sin embargo, de dejar a libre disposición del legislador este núcleo duro de los derechos a través del principio de reserva de ley. La teoría externa del contenido esencial es una de las más empleadas hoy en día para el establecimiento de restricciones y límites a los derechos fundamentales. Ésta consiste básicamente en la comprensión de los límites externos a los derechos, sin tener ningún marco referencial interno que predefina o preconciba el contenido esencial de los derechos $;{ }^{91}$ es decir, cualquier concreción dependerá directamente de las colisiones que surjan directamente con la existencia de derechos, bienes o principios constitucionales en colisión.

Ejemplo de lo anterior ha sido la concreción de contenidos esenciales como el principio de igualdad a través de la razonabilidad jurídica. Nos referimos específicamente al caso de los militares con VIH, separados de las fuerzas armadas por causa de inutilidad. Esto ha permitido una nueva forma de analizar las violaciones a los derechos fundamentales de manera más novedosa y creativa, siguiendo el modelo continental europeo de proporcionalidad. En este sentido, las sentencias de los tribunales constitucionales alemán y español, respectivamente. La dignidad humana y el libre desarrollo de la personalidad han sido dos principios desarrollados tardíamente por la Corte mexicana. Fue hasta inicios del siglo XXI, con el caso del cambio de sexo, que la Suprema Corte los reconociera como parte fundamental y estructural del sistema jurídico mexicano, e incluso como fundadores del resto de los demás derechos fundamentales, teniendo como inspiración la jurisprudencia y el derecho internacional y comparado. Asimismo, el libre desarrollo de la personalidad ha sido un principio a partir del cual la Suprema Corte ha derivado la creación de nuevos derechos que no habían sido inicialmente reconocidos en el texto constitucional, tales como el derecho a la imagen, privacidad, intimidad y protección de datos. Dicha situación resulta alentadora y creativa, la cual nos habla de una nueva forma de interpretación y argumentación en base a principios constitucionales.

En el Estado constitucional los derechos fundamentales merecen tutela y garantía mediante los procesos constitucionales de tutela de las libertades, sobre todo, en aquellas situaciones donde las personas son más vulnera-

91 León Bastos, Carolina y Sánchez Hernández, C. E., Manual de derechos fundamentales, México, Porrúa, 2012, p. 73. 
Esta revista forma parte del acervo de la Biblioteca Jurídica Virtual del Instituto de Investigaciones Jurídicas de la UNAM

bles; precisamente las minorías que antes eran desatendidas en el Estado de derecho, hoy reclaman garantías para volver efectivos los principios que en un inicio eran entendidos únicamente como normas programáticas, sujetas a los vaivenes y sinsabores de la política. El sistema constitucional mexicano se ha incorporado a este proceso desde el plano hermenéutico y normativo. Por su parte, la reforma constitucional de junio de 2011 ha consolidado una serie de transformaciones legislativas, necesarias para la plena implementación de un sistema integral para la defensa y protección de los derechos fundamentales. En tal sentido, el plano normativo ha sido satisfecho también con la reforma a la Ley de Amparo de principios de 2013, al incorporar, de igual forma, el derecho internacional de los derechos humanos. En este contexto, la fase de asimilación del test de proporcionalidad tiene lugar en el plano de la praxis judicial, a través de la incorporación de esta herramienta por los jueces constitucionales en distintos casos judiciales resueltos a finales de los años noventa, relacionados con la igualdad y razonabilidad de las leyes fiscales. Esta fase se termina con la implementación de este canon hermenéutico cuando se aborda el test de escrutinio estricto en relación a la aplicación igualitaria y no discriminatoria de distintos asuntos de índole administrativa.

El modelo de contenido esencial de derechos humanos, elegido por la jurisdicción constitucional mexicana es el de la teoría externa a partir del principio de proporcionalidad. Este modelo embrionario ha sido consolidado de manera paulatina a través de la solución de casos difíciles. Sin embargo, su empleo debe ir acompañado con el de una teoría material de los derechos fundamentales mediante una estructura flexible de principios y valores e indispensable para la concreción de los mismos.

\section{BIBLIOGRAFÍA}

ALEXY, Robert, El concepto y la naturaleza del derecho, trad. y estudio introductorio de Carlos Bernal Pulido, Madrid, Marcial Pons, 2008.

, en SEOANE, José Antonio (ed.), La institucionalización de la justicia, trad. de José Antonio Seoane et al., Granada, Comares, 2005.

- Teoría de la argumentación jurídica. La teoría del discurso racional como teoría de la fundamentación jurídica, trad. de Manuel Atienza e Isabel Espejo, Madrid, CEPC, 1997. 
Esta revista forma parte del acervo de la Biblioteca Jurídica Virtual del Instituto de Investigaciones Jurídicas de la UNAM

, Teoría de los derechos fundamentales, trad. de Carlos Bernal Pulido, 1a. reimp. de la 2a. ed., Madrid, Centro de Estudios Político Constitucionales, 2008.

- Tres escritos sobre derechos fundamentales y la teoría de los principios, presentación y trad. de Carlos Bernal Pulido, Bogotá, Universidad Externado de Colombia, 2003.

ATIEnZA, Manuel, Las razones del derecho. Teorías de la argumentación jurídica, México, UNAM, Instituto de Investigaciones Jurídicas, 2003.

y Ruiz Manero, Juan, Las piezas del derecho. Teoría de los enunciados jurídicos, Barcelona, Ariel, 1996.

Bernal Pulido, Carlos, El principio de proporcionalidad y los derechos fundamentales, Madrid, Centro de Estudios Políticos y Constitucionales, 2007.

, El derecho de los derechos (escritos sobre la aplicación de los derechos fundamentales), Bogotá, Universidad del Externado de Colombia, 2008.

BÖCKENFORDE, Ernst, Escritos sobre derechos fundamentales, trad. de Juan Luis Requejo Pagés e Ignacio Villaverde Menéndez, Baden-Baden, Nomos, 1993.

, "Origen y cambio del concepto de Estado de derecho", Estudios sobre el Estado de derecho y la democracia, trad. y prólogo de Agapito Serrano, R., Madrid, Trotta, 2000.

Borowski, Martin, La estructura de los derechos fundamentales, trad. de Carlos Bernal Pulido, Bogotá, Universidad Externado de Colombia, 2003.

Brage CAmazano, Joaquín, Los limites a los derechos fundamentales, Madrid, Dykinson, 2004.

CARbonell SÁnchez, Miguel, El canon neoconstitucional, Madrid, Trotta, 2011.

ClÉRICO, Laura, Die Struktur der Verhältnismäßigkeit, Baden-Baden, Nomos, 2000.

- El examen de proporcionalidad en el derecho constitucional, Buenos Aires, Editorial Universitaria de Buenos Aires, 2009.

DE Asís, Rafael, El juez y la motivación en el derecho, Madrid, Dykinson, 2006. 
Esta revista forma parte del acervo de la Biblioteca Jurídica Virtual del Instituto de Investigaciones Jurídicas de la UNAM

Del ReAl AlcalÁ, J. Alberto, Interpretación jurídica y neoconstitucionalismo, Bogotá, Universidad Autónoma de Occidente-Instituto de Derechos Humanos Fray Bartolomé de las Casas, 2011.

—_ "Cuestionamiento contemporáneo del ideal de certeza en el derecho: Hart-Zagrebelsky-Endicott", Boletín Mexicano de Derecho Comparado, México, núm. 131, 2011.

Dworkin, R., Los derechos en serio, Barcelona, Ariel, 2002.

ENDICOTT, Timothy A. O., "El derecho es necesariamente vago", trad. de J. Alberto del Real Alcalá y Juan Vega Gómez, Derechos y Libertades, Madrid, 2007.

— La vaguedad en el derecho, trad. de J. Alberto del Real Alcalá y Juan Vega Gómez, Madrid, Dykinson, 2007.

GAVARA DE CARA, J. C., Derechos fundamentales y desarrollo legislativo, la garantía del contenido esencial de los derechos fundamentales en la ley fundamental de Bonn, Madrid, Centro de Estudios Constitucionales, 1994.

GuAstini, Ricardo, Estudios de teoría constitucional, México, Fontamara, 2001.

HART, H. L. A., El concepto de derecho, trad. de Genaro R. Carrió, Buenos Aires, Abeledo-Perrot, 1961.

Hesse, Konrad, Escritos de derecho constitucional, Madrid, Fundación Coloquio Jurídico Europeo, 2011.

Kelsen, Hans, Teoría general de las normas, México, Trillas, 1994.

- Teoría general del derecho y del Estado, trad. de Eduardo García Máynez, México, UNAM, 1993.

-, Teoría pura del derecho, México, Porrúa-UNAM, 1993.

MüLlER, Friedrich, Arbeitsmethoden des Verfassungsrechts [Métodos de trabajo del derecho constitucional. Fundamentación general de una concepción de los métodos en el trabajo jurídico], trad. de Gómez de Arteche, Salvador, Madrid, Marcial Pons, 2006, edición bilingüe alemán-español.

Perelman, CH. y Olbrechts-TytecA, L., Tratado de la argumentación. La nueva retórica, trad. de Julia Sevilla Muñoz, Madrid, Biblioteca Romano Hispánica, Gredos, 1989.

PÉREZ LUÑO, Antonio Enrique, Los derechos fundamentales, Madrid, Tecnos, 2005. 
Esta revista forma parte del acervo de la Biblioteca Jurídica Virtual del Instituto de Investigaciones Jurídicas de la UNAM

Pozzolo, Susanna, Neocostitucionalismo e positivismo giuridico, Turín, Giappichelli, 2001.

PRIETO SANCHÍs, Luis, El constitucionalismo de los derechos, Madrid, Trotta, 2013.

\section{2.}

SÁNCHEZ GIL, Rubén, El principio de proporcionalidad, México, UNAM, Instituto de Investigaciones Jurídicas, 2007.

SMEND, Rudolf, Constitución y derecho constitucional, trad. de José Ma. Beneyto Pérez, Madrid, CEC, 1985.

SIECKMANN, Jan-R. (ed.), Derechos fundamentales, principios y argumentación: estudios sobre la teoría jurídica de Robert Alexy, Granada, Comares, 2011.

— El modelo de los principios del derecho, Bogotá, Universidad Externado de Colombia, 2006.

Toulmin, Stephen, Los usos de la argumentación, trad. de María Morrás y Victoria Pineda, Barcelona, Ediciones Península, 2007.

VIEWEGH, Theodor, "Sobre el desarrollo contemporáneo de la tópica jurídica", Tópica y filosofia del derecho, Barcelona, Gedisa, 1991.

VIOLA, Francesco y ZACCARIA, Giuseppe, Derecho e interpretación (elementos de una teoría hermenéutica del derecho), Madrid, Dykinson, 2007.

WrobleWSKI, Jerzy, Constitución y teoría general de la interpretación jurídica, Madrid, Civitas, 1985.

ZagrebelsKy, Gustavo, Historia y Constitución, Madrid, Trotta, 2005.

—_, El derecho dúctil, Madrid, Trotta, 1999.

Fecha de recepción: 16 de febrero de 2016.

Fecha de dictamen: 27 de marzo de 2017. 